\title{
МЕХАНИЗМЫ ВЛИЯНИЯ НЕТАРИФНОГО РЕГУЛИРОВАНИЯ НА ЭКОНОМИКУ
}

\section{MECHANISMS OF INFLUENCE OF NON-TARIFF REGULATION ON THE ECONOMY}

\section{A. Zyk}

Summary. The publication investigates the impact of the application of various groups of non-tariff restrictions on the economy. The mechanisms of technical barriers, sanitary and phytosanitary regulation, quotas and licensing, anti-dumping duties and export subsidies, as well as the consequences of their introduction on trade and public welfare are described.

Keywords: non-tariff measures, non-tariff regulation, trade restrictions, technical barriers to trade, anti-dumping duties, export subsidies, quotas, licensing.

\author{
Зык Анастасия Олеговна \\ Аспирант, Российский экономический университет \\ им. Г.В. Плеханова \\ nastiazyk@icloud.com
}

Аннотация. В работе исследуется влияние применения различных групп нетарифных ограничений на экономику. Описаны механизмы действия технических барьеров, санитарного и фитосанитарного регулирования, квотирования и лицензирования, антидемпинговых пошлин и экспортных субсидий, а также последствия их введения для торговли и общественного благосостояния.

Ключевые слова: нетарифные меры, нетарифное регулирование, торговые ограничения, технические барьеры в торговле, антидемпинговые пошлины, экспортные субсидии, квотирование, лицензирование.

Одна из первых попыток оценить взаимосвязь между использованием ограничительных стандартов и объемом торговли была предпринята в 1996 году английскими учеными [11]. Они обнаружили, что введение стандартов стимулирует торговлю. Так, на примере Великобритании было показано, что увеличение числа применяемых к товарам стандартов на 10\% повлекло за собой рост объемов как импорта (на 3,3\%), так и экспорта (на 2,3\%). Примерно в то же время их соотечественники, используя альтернативные методы оценки, получили вывод об отсутствии влияния стандартов на объем торговли [12]. Выходит, что кажущийся очевидным ограничительный эффект от их введения вовсе не обязательно возникает. Напротив, они могут даже стимулировать торговлю.

Учитывая разнообразие вариантов того, как такие меры влияют на торговлю, можно предположить, что характер этого влияния может зависеть от сектора экономики. Эта гипотеза нашла подтверждение в американском исследовании 2004 года, автор которого проанализировал взаимную торговлю между двенадцатью развитыми странами. Он сделал вывод о том, что в таких секторах как продовольственные товары, минеральное топливо и другая сырьевая продукция, эффект от применения стандартов был отрицательным. В сфере же химической промышленности и промышленного оборудования стандарты влияли на импорт положительно [8]. Такой эффект может быть объяснен тем, что стандарты 


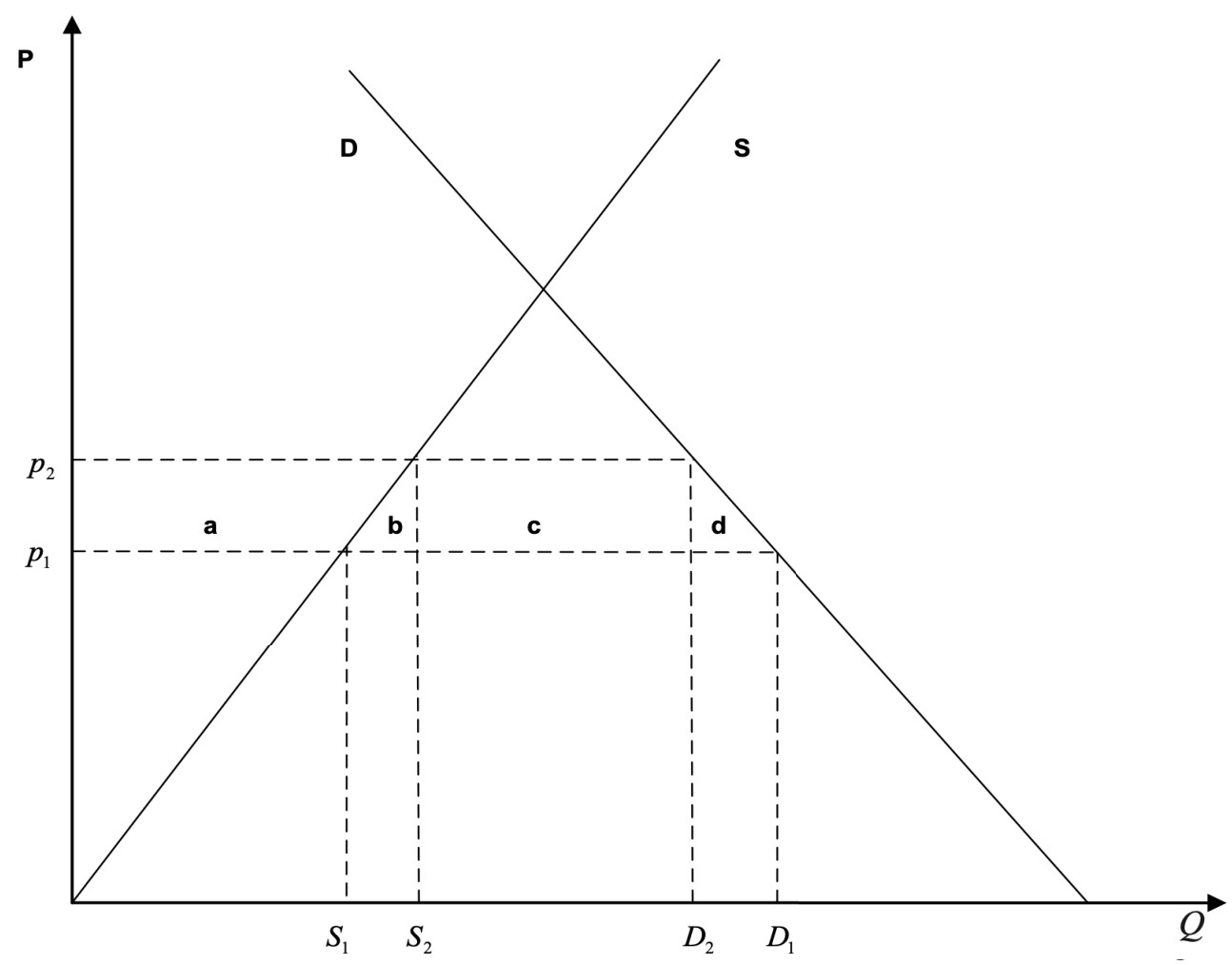

Рис. 1. Эффект от применения стандартов [1]

дают производителю некую информация о предпочтениях на том или ином рынке. И в более высокотехнологичных областях затраты на приведение товара в соответствие этим стандартам окупаются ростом спроса. Эти выводы позднее были подтверждены и в других исследованиях $[7,3]$.

Другим критерием, от которого может зависеть характер влияния таких мер, как технические барьеры и санитарное и фитосанитарное регулирование, является уровень развития страны. В основном введение стандартов негативно сказывается на торговых потоках из развивающихся стран в развитые. Такой вывод был получен в исследовании Андерса, рассматривающем введение новых санитарных мер в отношении морепродуктов, импортируемых в США. Объем экспорта для поставщиков из развивающихся стран снизился после введения мер, в то время как производители из развитых стран свой объем торговли, наоборот, увеличили [1].

В той же работе было отмечено, что влияние стандартов на объем торговли может зависеть и от размера фирмы. Среди поставщиков из развивающихся стран были не только те, кто потерял свою долю американского рынка после введения мер, были и те, кто нарастил экспорт. Если рассматривать приведение своей про- дукции в соответствие стандартам как постоянные издержки, то наибольший урон от них получат небольшие предприятия. Крупные же предприятия выиграют от эффекта масштаба и, возможно, от освободившейся доли рынка. Таким образом, еще одним эффектом введения мер в форме стандартов может являться уменьшение количества поставщиков импортируемой в страну продукции, и следовательно меньшее разнообразие продукции на рынке.

Помимо расходов на приведение товара в соответствие требованиям, непременно возникают расходы на тестирование и сертификацию, которые в свою очередь включаются в цену продукции. Дополнительные расходы возникают в случае, если компания осуществляет экспорт в страны с разными требованиями к продукции и ее сертификации. Могут появиться расходы на изменение упаковки и дизайна товара. Проведение процедур оценки соответствия требованиям занимает время, а для многих товаров время является важным фактором прибыльности. В особенности это касается товаров с ограниченным сроком годности, в частности, продовольственной продукции.

В работе В.В.Идрисовой приведен анализ влияния стандартов на торговые потоки с использованием моде- 


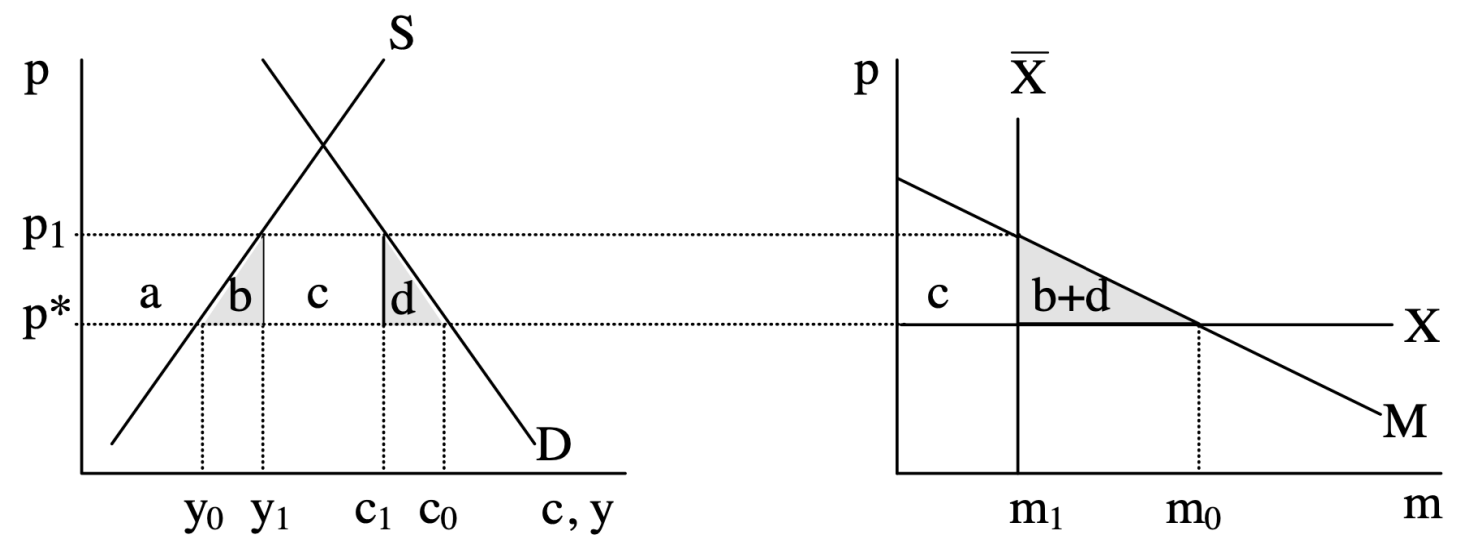

Рис. 2. Эффект от применения квоты [6]

ли частичного равновесия на рынке товаров [1]. До введения мер при цене $\mathrm{p}_{1}$ дефицит на внутреннем рынке составит величину $\mathrm{D}_{1}-\mathrm{S}_{1}$, тогда в условиях открытой экономики это количество займет импорт. Введение мер для иностранных производителей повлечет за собой повышение цены до уровня $\mathrm{p}_{l}$. Тогда внутреннее предложение возрастет до $S_{1}$, а спрос уменьшится то $D_{2}$. Величина импорта теперь составит теперь $\mathrm{D}_{2}-\mathrm{S}_{2}$. B результате общественное благосостояние понесет убытки, равные сумме площадей треугольников b и d.

Далее перейдем к квотированию и лицензированию. Импортная квота представляет собой ограничение количества ввозимого товара путем выдачи лицензии. Расходы на лицензирование обычно влекут за собой повышение цены. Причем в отличии от тарифов, доход от выдачи лицензий не обязательно уходит государству-импортеру, так как право на выдачу лицензий может принадлежать организациям за рубежом.

Введение импортной квоты влечет за собой повышение цены и на внутреннем рынке импортера, так как предложение извне становится меньше, чем было необходимо для удовлетворения спроса.

На рисунке 2 показано влияние введения импортной квоты в условиях совершенной конкуренции и открытого рынка для малой страны, на первом графике изображен внутренний рынок, на втором - рынок импорта. Изначально имеем внутренний спрос с ${ }_{0}$ и внутреннее предложение $y_{0}$ при мировой цене р*. Разница между величиной внутренних спроса и предложения компенсируется импортом в объеме $\mathrm{c}_{0}-\mathrm{y}_{0}=\mathrm{m}_{0} . \mathrm{M}=\mathrm{D}-\mathrm{S}$ - кривая спроса на импорт, X - кривая предложения импорта.

$$
\overline{\mathrm{X}}
$$

Введение импортной квоты означает невозможность импорта свыше величины $\mathrm{m}_{l}$, вследствие чего цена повышается до уровня $\mathrm{p}_{l}$, внутреннее предложение повышается до $\mathrm{y}_{l}$, внутренний спрос снижается до $\mathrm{c}_{l}$. Потери потребителя составляют $\mathrm{a}+\mathrm{b}+\mathrm{c}+\mathrm{d}, \mathrm{a}-$ выигрыш производителя. Площадь прямоугольника с - есть выигрыш того, кто владеет лицензией на импорт. Возможно несколько вариантов. При первом импортная лицензия принадлежит местным продавцам, которые могут приобретать товар на мировом рынке по цене $\mathrm{p}^{*}$ и затем продавать его на внутреннем рынке по цене $\mathrm{p}_{1}$, соответственно получая выгоду в размере с. При втором лицензии могут распределяться государством-импортером посредством аукциона, и тогда выигрыш в размере с отойдет государству. Третьим вариантом является так называемое «добровольное ограничение экспорта», в этом случае страна-экспортер распределяет квоту между своими продавцами, и тогда избыток в размере с уходит к ним.

Следующий вид мер - антидемпинговые пошлины. Они принимаются тогда, когда для импортера имеет место продажа на внешнем рынке по ценам ниже, чем на внутреннем (без учета издержек на транспортировку).

Обычно введение импортной пошлины позитивно отражается на условиях торговли для местных производителей, так как они могут увеличить объем своего производства и как следствие повысить свою эффективность. Эффект применения антидемпинговых пошлин напротив отрицательный. Данные меры негативно влияют на условия внутренней торговли, а также понижают общее благосостояние импортирующей страны. Рассмотрим этот процесс подробнее.

Антидемпинговый процесс проходит несколько стадий. Начинается он с инициирования расследования, в результате которого должно быть определено, действительно ли цена на импортируемый товар ниже так называемой справедливой цены. Для этого цена импортируемого товара сравнивается с его ценой в стране 

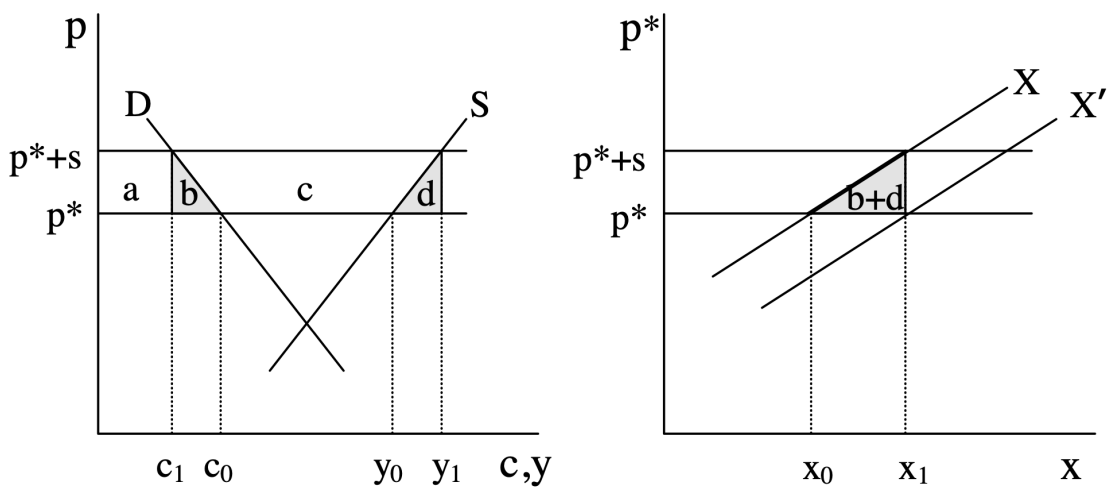

Рис. 3. Эффект от применения экспортной субсидии [6]

производителя. Чтобы исключить влияние транспортных издержек берется цена при поставке на условиях ФОБ. Если цена на рынке производителя больше, чем цена ФОБ, значит торговля происходит по цене ниже справедливой. За этим следует установление антидемпинговой пошлины на следующий период в размере ((цена на рынке производителя/цена ФОБ)-1)*100\%. Что примечательно, размер антидемпинговой пошлины на следующий период зависит обратно пропорционально от цены в текущем периоде. А это значит, что производителю в текущем периоде будет выгодно поднять цену, чтобы в следующем периоде заплатить пошлину меньше. Тогда страна-импортер не получает пошлину и одновременно с этим получает товар по более высокой цене.

Помимо этого, инициирование антидемпингового расследования уже само по себе может влиять на импорт, а именно на его объем. Так, например, в США начало антидемпинговых разбирательств в среднем снижало объем импорта почти в два раза [10]. В исследовании CHOI был получен результат, согласно которому введение антидемпинговой пошлины снижает объем импорта на 30\%, а повышение антидемпинговой пошлины на 1\% вызывает снижение импорта из конкретной страны на 0,43-0,51\%. [5]. Однако это уменьшение импорта из страны, затронутой пошлиной, быстро возмещается увеличением импорта из других импортирующих стран, а следовательно влияние на общий объем импорта из всех государств носит лишь временный характер.

Еще одна большая группа мер - это экспортные субсидии, предоставляемая государством финансовая помощь отечественным экспортерам. Рассмотрим ее влияние в условиях совершенной конкуренции. Слева на рисунке 3 изображены кривая внутреннего спроса D и кривая предложения S при мировой цене $\mathrm{p}^{*}$. Объем импорта в таком случае равен $\mathrm{x}_{0}=\mathrm{y}_{0}-\mathrm{c}_{0}$ (на графике справа), кривая X=S-D - показывает объем предложения экспорта.

Если установить экспортную субсидию в размере $s$ для внутренних производителей, то они будут получать за свой товар, продаваемый на внешнем рынке выручку в размере $p^{*}+s$. Соответственно, теперь и на внутреннем рынке продавать за цену, меньшую $\mathrm{p}^{*}+\mathrm{s}$ отечественным производителям не выгодно, значит и внутренняя цена также увеличится на s. Повышение цены на внутреннем рынке повлечет за собой снижение спроса до с1 и рост предложения до у1, экспорт составит х1=y1-с1. А следовательно произойдёт смещение кривой предложения экспорта вниз.

Тогда потери потребителей составят площадь $\mathrm{a}+\mathrm{b}$, расходы государства на выплату субсидии $b+c+d$. Невосполнимые потери общественного благосостояния $\mathrm{b}+\mathrm{d}$, то есть страна проигрывает от применения экспортной субсидии.

Но экспортная субсидия не всегда вызывает снижение общественного благосостояния. В случае существования на рынке олигополии Курно новое равновесие после введения экспортной субсидии будет достигнуто в точке с возросшим экспортом отечественного производителя и сниженным экспортом иностранного конкурента [4]. Соответственно, прибыль отечественной фирмы вырастет, а изменения в общественном благосостоянии будут равны этой дополнительной прибыли.

Таким образом, несмотря на различные механизмы воздействия нетарифных мер (повышение цен, снижения объема торговли, уменьшение числа продавцов и так далее), общим результатом всегда является снижение общественного благосостояния, и любое введение нового ограничения торговли должно происходить только при действительной необходимости. 


\section{ЛИТЕРАТУРА}

1. Идрисова В. В. Теоретические вопросы применения нетарифных мер регулирования во внешней торговле // Научные труды. Институт экономической политики имени Е. Т. Гайдара.—-2011.— 149 с.

2. Anders S.M. and Caswell J. A. Standards as Barriers Versus Standards as Catalysts: Assessing the Impact of HACCP Implementation on U.S. Seafood Imports // American Journal of Agricultural Economics. — 2009.— № 91(2). — p.310-321.

3. Blind K. The impacts of innovations and standards on trade of measurement and testing products: empirical results of Switzerland's bilateral trade flows with Germany, France and the UK // Information Economics and Policy.— 2001.— № 13(4).— p. 439-460.

4. Brander J.A. and Spencer B. (1985). Export Subsidies and International Market Share Rivalry // Journal of International Economics. — № 16. — p. 83-100.

5. CHOI Nakguoon Economic Effects of Anti-Dumping Duties: Protectionist Measures or Trade Remedies? // KIEP Working Paper — 2016. — $41 \mathrm{p}$.

6. Feenstra R. Advanced International Trade: Theory and Evidence — 2002. - $657 \mathrm{p}$.

7. Li Y., Beghin J. C. A meta-analysis of estimates of the impact of technical barriers to trade // Journal of Policy Modeling. — 2012. — № 34(3). — p. 497-511.

8. Moenius J. Information versus Product Adaptation: The Role of Standards in Trade // Northwestern University, Kellogg School of Management, International Business and Markets Research Center Working Paper.-2004.— $41 \mathrm{p}$.

9. NTM to Trade Economic and Policy issues for developing countries // UNCTAD. Geneva. — 2013 [Электронный pecypc] — URL: https://unctad.org/en/ PublicationsLibrary/ditctab20121_en.pdf (дата обращения 24.05.2020)

10. Staiger Robert W. and Frank A. Wolak The Effect of Antidumping Law in the Presence of Foreign Monopoly // Journal of International Economics. - 1992. № 32. - p. 265-287.

11. Swann G. P. Temple P. and Shrumer M. Standards and Trade Performance: the UK Experience // Economic Journal.— 1996.— № 106(438).— p. $1996-1297$.

12. Temple P. and Urga G. The competitiveness of UK Manufacturing: Evidence from Imports // Oxford Economic Papers. — 1997.— № 49(2).— p. $207-227$.

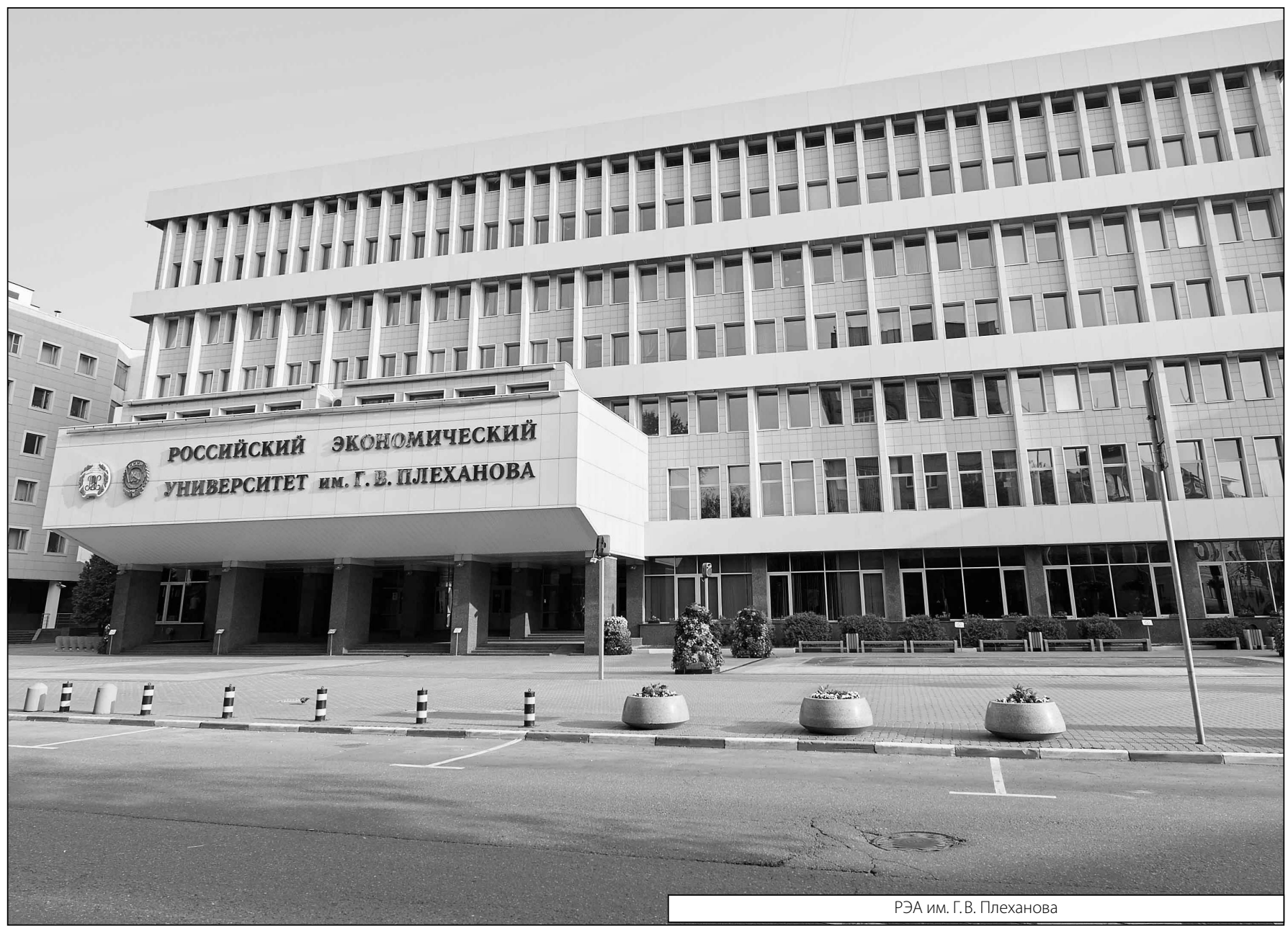

